\title{
Characteristics of magnetic carriers responsible for Late Paleozoic remagnetization in carbonate strata of the mid-continent, U.S.A.
}

\author{
Gang Lu ${ }^{a, 1}$, Stephen Marshak ${ }^{a}$ and Dennis V. Kent ${ }^{b}$ \\ ${ }^{a}$ Department of Geology, University of Illinois, $1301 \mathrm{~W}$. Green St., Urbana, IL 61801 (U.S.A.) \\ ${ }^{b}$ Lamont-Doherty Geological Observatory, Palisades, NY 10964 (U.S.A.)
}

Received November 15, 1989; revised version accepted April 11, 1990

\begin{abstract}
\end{abstract}
\begin{abstract}
Magnetic analysis of carbonate strata of the mid-continent region of the United States indicates that the Late Paleozoic remagnetization already recognized in the Appalachians also affects almost the entire mid-continent. Magnetic intensity is regionally variable, with more intense magnetizations occurring on intracratonic arches. Magnetization is carried predominately by magnetite, which often occurs in tiny hollow spheroids composed of well formed octahedral microcrysts. Spheroid chemistry and morphology suggests that the magnetite is authigenic, composed of iron extracted from pre-existing pyrite or clay. The timing of the remagnetization, the character of the magnetite, and the regional variation in magnetic intensity support the idea that the remagnetization is a diagenetic consequence of tectonically-driven brine migration.
\end{abstract}

\section{Introduction}

In recent years, pervasive remagnetization has been recognized in the sedimentary strata of the Appalachian/Ouachita fold-thrust belt, Appalachian basin, Arkoma basin, and in scattered localities of the mid-continent region [e.g., 1-7]. Most measurements indicate that the dominant remagnetization occurred during the Kiaman long reversed polarity interval (Late Pennsylvanian/ Early Permian), and thus about the time of the Alleghanian/Ouachita orogeny. Because of this temporal and spatial association, many authors have suggested that the remagnetization was triggered by the orogeny [e.g., 3-9]. A favored driving mechanism appears to be uplift of groundwater recharge areas during orogenesis, which creates hydrostatic pressure sufficient to drive basin brines toward the continental interior [9]. These warm brines react with strata as they pass, leading not only to remagnetization, but also to various diagenetic effects (dolomitization, feldspathization,

\footnotetext{
1 Present address: Department of Geology and Geophysics, Louisiana State University, Baton Rouge, LA 70803-4101, U.S.A.
}

smectite illitization), ore formation, and petroleum migration [3-16].

Though much is already known about the Kiaman remagnetization, there are still several outstanding questions including: (1) how widespread are the effects of the event in mid-continent North America, and (2) what are the characteristics (e.g., mineralogy, morphology, origin etc.) of the magnetic carriers and how did they form? Our inital results [17] demonstrate that evidence for Kiaman remagnetization is widespread in the mid-continent (Fig. 1), though at several sites in Iowa and Minnesota, magnetizations proved to be very weak or unstable and thus the presence or absence of Kiaman remagnetization could not be determined. In addition, we show that there is a spatial association between remagnetization and regional arches; more intense magnetizations were measured in samples on or near the regional arches [17]. The details of our paleomagnetic and rockmagnetic measurements will be dealt with in a separate paper (Kent et al., in prep.). The principal purpose of the present paper is to describe the magnetic carriers. We were able to obtain remarkably clear SEM images of the magnetic grains, as well as EDX and XRD analyses of the grains. Earlier studies have noted and illustrated 


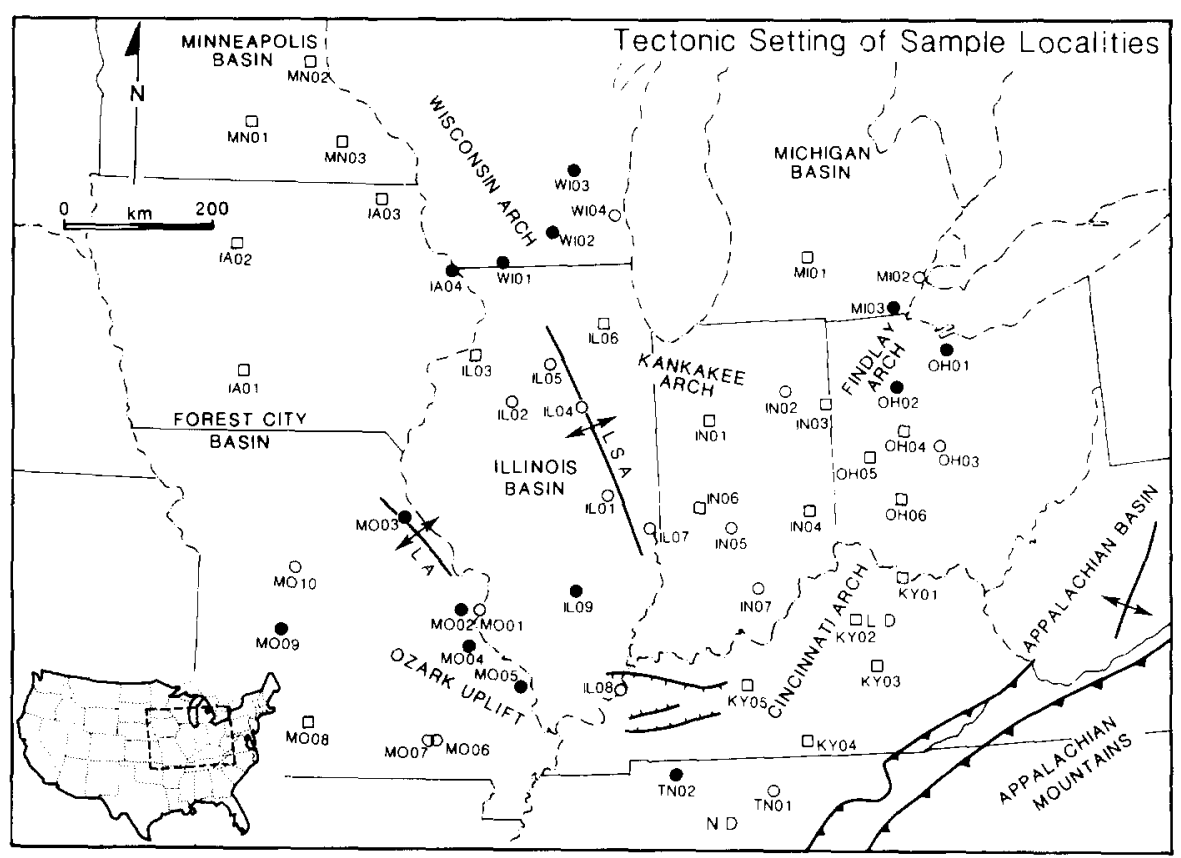

Fig. 1. Map of the sample localities. Solid circles $=$ localities where samples have an ARM measurement greater than $4 \mathrm{~mA} / \mathrm{m}$; open circles $=$ localities where samples have an ARM measurement smaller than $4 \mathrm{~mA} / \mathrm{m}$; squares $=$ localities where the magnetization of the samples was unstable and the Kiaman pole was not identified. ARM measurements are only for a subset of samples. $L A=$ Lincoln Anticline; $L S A=$ La Salle Anticlinal Belt; $N D=$ Nashville Dome.

tiny botryoidal [3], spherulitic [18,19], and spheroidal [20] grains in North America Paleozoic strata. These grains are interpreted to be diagenetic magnetite, and are considered to be the predominant magnetic carriers in the carbonate rocks. Our results demonstrate that these grains are also present throughout the mid-continent, and that there are four distinct morphological classes of magnetic carriers. Overall, the observations reported in this paper support the proposal that the carriers are of diagenetic origin and the magnetization is most probably a chemical remanent magnetization.

\section{Methods}

We collected about 500 oriented cores in carbonate rocks at 53 sites in the mid-continent region (Illinois, Indiana, Iowa, Ohio, Kentucky, Tennessee, Missouri, Minnesota, Michigan, Wisconsin; Fig. 1, Table 1). Samples were obtained from both limestone and dolomite beds of all ages from Cambrian through Pennsylvanian which are exposed in quarries and road cuts. The natural remanent magnetization of these samples is variable, but in general is very weak. Likewise, magnetic susceptibilities are very low; they are on the order of $10^{-6} \mathrm{emu} / \mathrm{Oe} \mathrm{cc}$ (Kent et al., in prep.). These data likely reflect the low concentration of the magnetic carriers in these rocks. Thus, in order to visually examine the magnetic carriers efficiently, we extracted them from the bulk rock. To do this, the rock was pulverized and placed in a solution $1 N$ acetic acid buffered with sodium acetate to a $\mathrm{pH}$ of 5 . Each day for about three weeks, the reagent was changed and the mixture of reagent and rock-powder residue was sonified. About $5 \%$ by weight of the original rock remained after dissolution. This residue was mixed with distilled water and passed through a Frantz L-1 isodynamic magnetic separator. Magnetic separation yielded an extract that was about $5 \%$ by weight of the original residue, or about $0.25 \%$ of the total rock.

Examination of the concentrated magnetic extract was carried out using a variety of techniques. A JEOL-840A scanning-electron microscope (SEM) permitted us to observe the grain mor- 
TABLE 1

Characteristics of samples used for rock-magnetic measurements

\begin{tabular}{|c|c|c|c|c|c|c|c|}
\hline Sample no. & Lithology & Age & ARM & Sample no. & Lithology & Age & ARM \\
\hline IA0105 & Coarse-grained calcarentite & IPmk & 1.553 & MN0105 & Coarse-grained dolomite & LO & 1.506 \\
\hline IA0205 & Coarse-grained calcarentite & $\mathrm{Mm}$ & 0.296 & MN0204 & $\begin{array}{l}\text { Coarse grained dolomitic } \\
\text { calcarentite }\end{array}$ & MO & 0.813 \\
\hline IA0302 & Coarse-grained calcarentite & $\mathrm{MO}$ & 0.632 & $\mathrm{MN} 0307$ & Coarse-grained calcirudite & MO & 0.728 \\
\hline IA0408 & $\begin{array}{l}\text { Coarse-grained dolomitic } \\
\text { calcarentite }\end{array}$ & MO & 5.511 & MO0105 & Fine-grained calcisiltite & $\mathrm{Mm}$ & 0.434 \\
\hline IL0108 & Coarse-grained calcarentite & $\mathrm{D}$ & 3.112 & MO0207 & $\begin{array}{l}\text { Fine-grained dolomitic } \\
\text { calcisiltite }\end{array}$ & MO & 4.517 \\
\hline IL0202 & Coarse-grained calcarentite & IP & 2.895 & MO0301 & $\begin{array}{l}\text { Fine-grained dolomitic } \\
\text { calcilutite }\end{array}$ & MO & 4.181 \\
\hline IL0305 & Coarse-grained calcarentite & $\mathbf{S}$ & 0.255 & MO0405 & Coarse-grained calcarentite & MO & 4.135 \\
\hline IL0402 & Coarse-grained calcarentite & $\mathrm{UIPb}$ & 2.587 & MO0506 & Fine-grained dolomite & MO & 13.876 \\
\hline IL0505 & Coarse-grained calcarentite & MIPm & 0.617 & MO0605 & Coarse-grained dolomite & UC & 1.764 \\
\hline IL0603 & Coarse-grained dolomite & $\mathbf{S}$ & 1.542 & MO0706 & Coarse-grained dolomite & LO & 1.326 \\
\hline IL0707 & Coarse-grained calcirudite & $\mathrm{UIPb}$ & 0.609 & MO0803 & Coarse-grained calcarentite & Mko & 0.198 \\
\hline IL0807 & Coarse-grained calcarentite & $\mathrm{Mv}$ & 2.734 & MO0908 & Fine-grained dolomite & LO & 17.036 \\
\hline IL0906 & $\begin{array}{l}\text { Coarse-grained dolomitic } \\
\text { calcarentite }\end{array}$ & UIPm & 23.176 & MO1009 & $\begin{array}{l}\text { Fine-grained dolomitic } \\
\text { calcisiltite }\end{array}$ & Mko & 3.582 \\
\hline IN0103 & Fine-grained dolomite & US & 0.888 & OH0106 & $\begin{array}{l}\text { Coarse-grained dolomitic } \\
\text { calcarentite }\end{array}$ & MD & 4.544 \\
\hline IN0204 & Coarse-grained calcarentite & S & 3.994 & $\mathrm{OH} 0201$ & Coarse-grained dolomite & US & 62.259 \\
\hline IN0308 & Fine-grained dolomite & S & 1.083 & $\mathrm{OH} 0305$ & Coarse-grained dolomite & MD & 3.638 \\
\hline IN0414 & Coarse-grained calcarentite & UO & 0.862 & $\mathrm{OH} 0403$ & Coarse-grained dolomite & UD & 0.697 \\
\hline IN0502 & Coarse-grained calcirudite & LM & 1.898 & OH0506 & Coarse-grained calcarentite & LS & 0.295 \\
\hline IN0601 & Fine-grained calcisiltite & $\mathrm{UM}$ & 0.311 & OH0604 & Coarse-grained dolomite & MS & 0.622 \\
\hline IN0708 & Coarse-grained calcisiltite & MM & 1.441 & TN0104 & Fine-grained calcilutite & Omu & 1.181 \\
\hline KY0104 & Coarse-grained calcarentite & UO & 0.658 & TN0205 & Fine-grained calcisiltite & $\mathrm{Mm}$ & 21.301 \\
\hline KY0206 & Coarse-grained calcarentite & MO & 0.401 & W10109 & Coarse-grained dolomite & MO & 4.943 \\
\hline KY0301 & Fine-grained calcisiltite & UO & 3.700 & WI0207 & Coarse-grained dolomite & MO & 4.570 \\
\hline KY0408 & Fine-grained dolomite & $\mathrm{D}$ & 3.174 & W10306 & Coarse-grained dolomite & MO & 5.797 \\
\hline KY0505 & Coarse-grained calcarentite & $\mathrm{Mc}$ & 0.657 & WI0402 & Coarse-grained dolomite & S & 1.408 \\
\hline MI0103 & Fine-grained calcisiltite & UM & 1.097 & & & & \\
\hline MI0206 & Coarse-grained dolomite & MD & 0.259 & & & & \\
\hline MI0311 & $\begin{array}{l}\text { Coarse-grained dolomitic } \\
\text { calcarentite }\end{array}$ & US & 16.531 & & & & \\
\hline
\end{tabular}

ARM is measured in $\mathrm{mA} / \mathrm{m}$. Grain-size: Calcilutite $(10-30 \mu \mathrm{m})$; Calcisiltite $(30-60 \mu \mathrm{m})$; Calcarentite $(60 \mu \mathrm{m}-2.5 \mathrm{~mm})$; Calcirudite (greater than $2.5 \mathrm{~mm}$ ). Age of geologic units is specified by a letter $(\mathrm{C}=\mathrm{Cambrian}, \mathrm{O}=$ Ordovician, $\mathrm{S}=\mathrm{Silurian}, \mathrm{D}=\mathrm{Devonian}$, $\mathbf{M}=$ Mississippian, IP = Pennsylvanian). The letter before the system symbol represents the subdivision in that system ( $L=L$ ower; $\mathrm{M}=$ Middle; $\mathrm{U}=$ Upper). The lower-case letter after the system symbol represents the stages or subgroups. (UIPm $=\mathrm{Matton}$ Subgroup and McLeansboro Supergroup of the Upper Pennsylvanian. UIPb = Bond Subgroup and McLeansboro Supergroup of the Upper Pennsylvanian. IPmk = Kansas City Subgroup and Missourian Supergroup of the Middle Pennsylvanian. Mm $=$ Meramecian Supergroup of the Mississippian. Mc = Chesterian Supergroup of the Upper Mississippian. Mv=Valmeyeran Supergroup of the Middle Mississippian. Mko = Kinderhookian-Osagian Subgroup of the Lower Mississippian. Omu = Undivided Middle Ordovician and Upper Ordovician strata.

phology, and the energy-dispersive X-ray analyzer (EDX) attached to the SEM permitted us to determine the identity of elements in individual grains. We used high-resolution X-ray diffraction (XRD) analysis of the concentrated magnetic extract to confirm the mineralogy of grains present, and optical petrography (transmitted and reflected) to examine original rock fabrics. Rock- magnetic and paleomagnetic measurements were carried out at Lamont-Doherty Geological Observatory.

\section{Description of magnetic carriers}

We examined the characteristics of magnetic carriers in ten samples in detail. SEM examination 

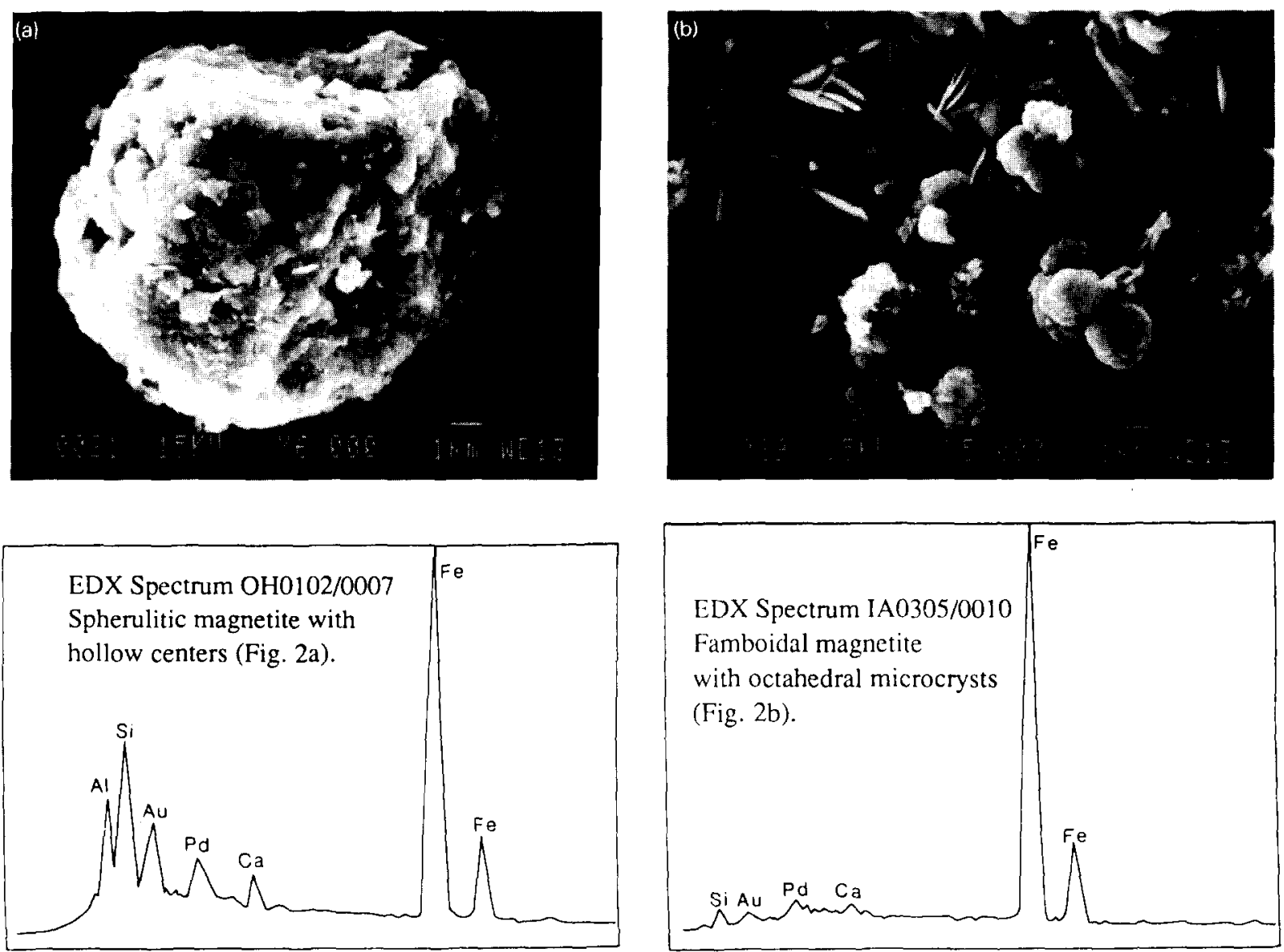

Fig. 2. SEM photomicrographs and EDX spectra for candidate magnetic carriers from concentrated magnetic extracts of carbonate rocks. The Au and Pd peaks on the EDX spectra are due to the coating put on during SEM sample preparation. (a) A cluster of spherulitic grains (magnetite?). Broken spherules reveal hollow centers. An authigenic K-feldspar grain is in the upper right corner. $\mathrm{Fe}$ of the grain and $\mathrm{Si}, \mathrm{Al}$, and $\mathrm{Ca}$ of the coating (probably authigenic clay) are indicated on the EDX spectrum. Scale bar $=1 \mu \mathrm{m}$. (b) Clean framboidal iron-rich grain (magnetite?) with perfectly developed octahedral microcrysts. Scale bar $=1 \mu \mathrm{m}$. (c) Partially coated framboidal grain. Framboidal character of the aggregate is almost obscured by silicate coating (probably authigenic clay). Scale bar $=1 \mu \mathrm{m}$. (d) Botryoidal grain (goethite or hematite?) with flaky-habit aggregates (hematite?). The EDX spectrum shows two intense Fe peaks. Scale bar $=1 \mu \mathrm{m}$. (e) Flaky-habit aggregate (hematite?) and botryoidal grains (hematite or goethite?). The EDX spectrum shows two strong Fe peaks. Scale bar $=10 \mu \mathrm{m}$. (f) Framboidal and spheroidal pyrite in dolomite. K-feldspar grain is on the left. Scale bar $=10 \mu \mathrm{m}$.

of the concentrated magnetic extract indicates that it contains about $1 \%$ iron-rich and sulfur-free grains, which are considered to be magnetic carriers. We roughly estimate the concentration of these grains in the original bulk rocks to be no more than $5 \% \times 5 \% \times 1 \%=25 \mathrm{ppm}$ by weight. Based on our study, four morphological types of magnetic carriers can be distinguished from one another in the extracts: spheroidal grains, framboidal aggregates, botryoidal aggregates, and flaky-habit aggregates.

\subsection{Spheroidal grains}

Spheroidal grains (spheroids) are the most common morphological type observed in our samples. These grains are about 5-15 $\mu \mathrm{m}$ in diameter, and they have a somewhat bumpy surface. A few of the observed spheroids were broken, and reveal a hollow center (Fig. 2a). EDX spectra of the samples show very strong $\mathrm{Fe}$, moderately strong $\mathrm{Si}$, $\mathrm{Al}$, and $\mathrm{Ca}$ peaks, and no $\mathrm{S}$ peaks, suggesting that the spheroids are composed of iron oxides (magnetite, goethite, or hematite) coated with silicate 

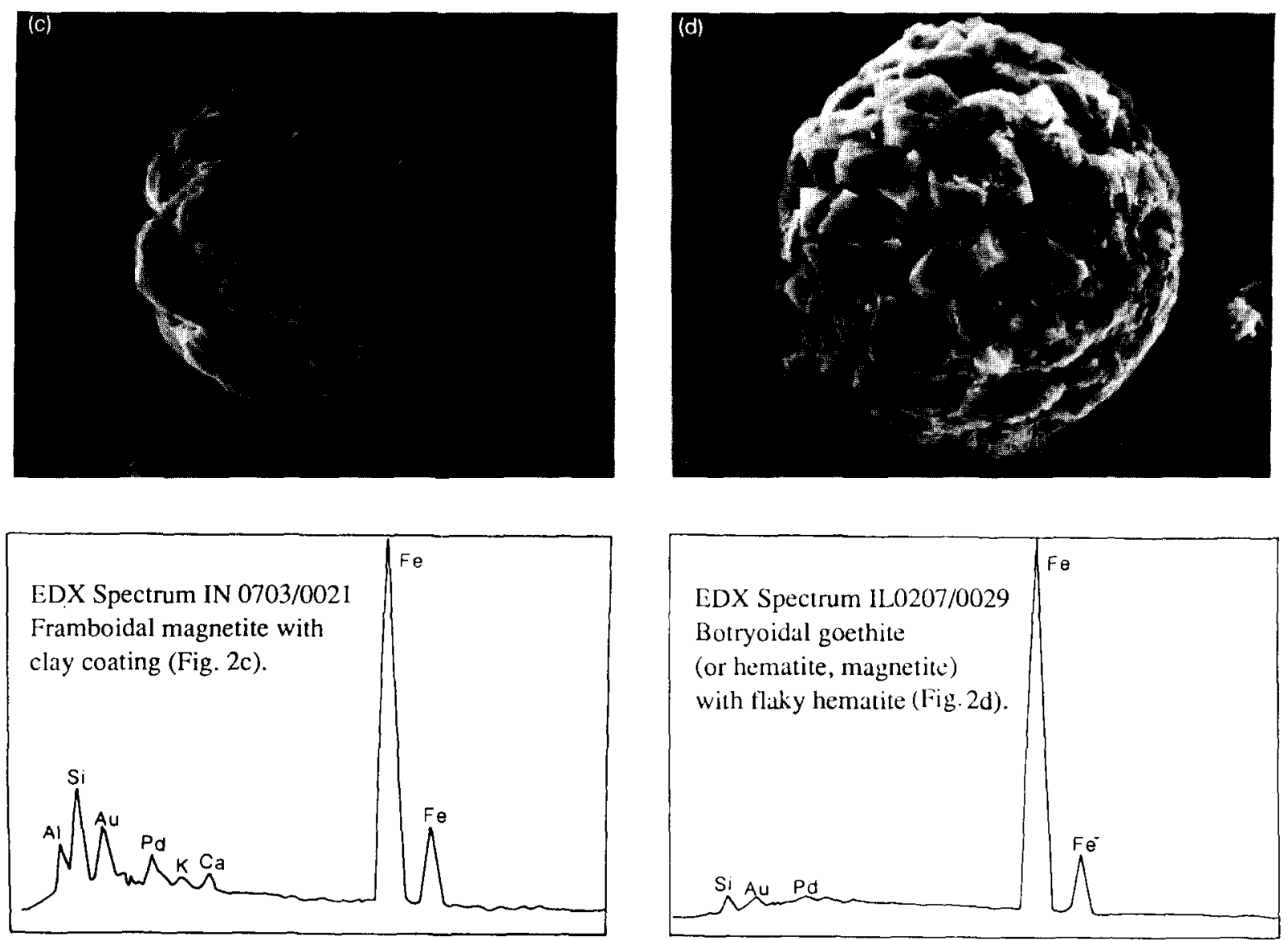

Fig. 2 (continued).

minerals (probably authigenic clays). Absence of $\mathrm{S}$ peaks indicates that the spheroids cannot be composed of iron sulfides (pyrite, pyrrhotite, or marcasite).

\subsection{Framboidal aggregates}

A "framboidal aggregate" (framboid) is a spheroidal cluster that consists of many smaller, discrete, equant individual crystals called microcrysts. The framboids found in the concentrated magnetic extracts of our samples range in size between 10 and $20 \mu \mathrm{m}$, and are composed of individual microcrysts that range in size between 1 and $3 \mu \mathrm{m}$. We found several spectacular examples in which the microcrysts displayed an unmistakable octahedral crystal habit (Fig. 2b). In most examples, the microcrysts were partially hidden by a thin amorphous-looking coating (Fig. 2c). EDX analysis of the grains shows that well exposed octahedral crystals have only dominantly strong Fe peaks (Fig. 2b), whereas the partially coated grains have not only $\mathrm{Fe}$ peaks but also $\mathrm{Si}, \mathrm{Al}$, and $\mathrm{Ca}$ peaks (Fig. 2c). The grain shown in Fig. 2c looks quite spheroidal, but individual microcrysts are slightly visible alluding to the underlying framboidal morphology. We infer that the octahedral crystals are iron oxides, that the framboids are therefore composed of clusters of iron-oxide grains, and that at least some spheroidal grains are actually framboids with an authigenic clay coating.

The well developed octahedral habit and absence of sulfur peaks suggest that the microcrysts are most likely magnetite, and not solid goethite or hematite. However, the framboids observed in thin section and the concentrated magnetic extracts suspended in mineral oil are somewhat red in color, suggesting the possibility of goethite/ 

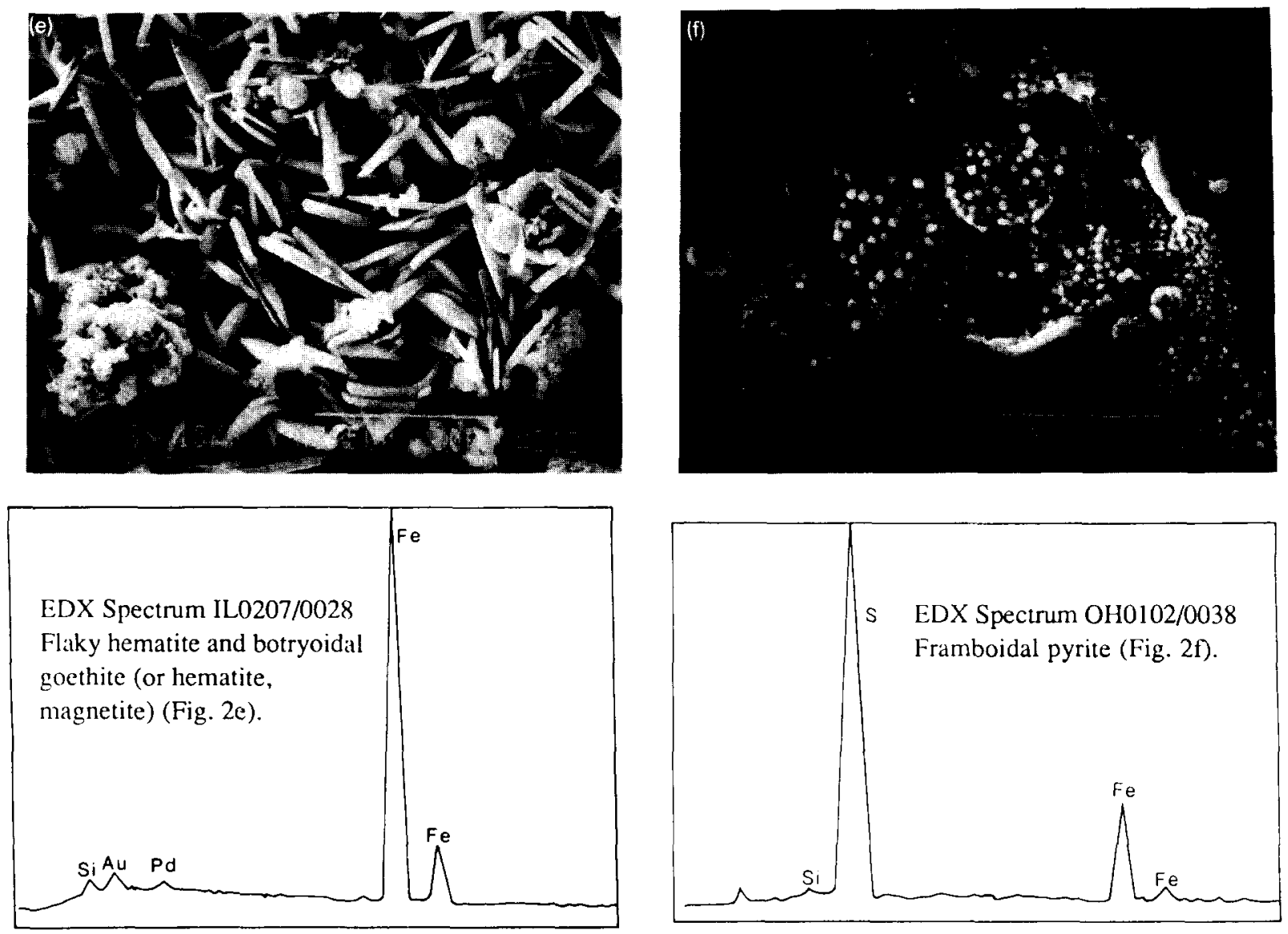

Fig. 2 (continued).

hematite alteration on the surface of the framboids. We also note that some grains of pyrite, identified by their appearance in reflected-light petrographic analysis, are partially altered by pseudomorphic replacement to goethite/hematite. There is a possibility that some of the red framboidal grains contain goethite that formed as an oxidation product derived from framboidal pyrite during sample treatment in solvent, but we do not consider this possibility to be likely because such a reaction would probably not completely remove sulfur from the precursor pyrite. We assume that goethite is a low-temperature alteration product reflecting shallow-level reaction of rocks with meteoric water, and that it is not associated with the remagnetization.

\subsection{Botryoidal and flaky-habit aggregates}

In addition to the framboidal and spheroidal grains described above, an iron-rich and sulfur-free mineral, as identified by EDX spectra, occurs in two other forms. The first is in grape-like clusters of spheroids referred to as botryoidal aggregates (Fig. 2d). Botryoidal aggregates could be a morphological form for magnetite, hematite, or goethite, but the distinction between these minerals cannot be made on the basis of EDX spectra alone. The second form is in clusters of tiny flakes. The flakes were extracted from a reddish scum that formed on the surface of reagent during dissolution of a few samples (e.g., IL0207). The flakes are 1-3 $\mu \mathrm{m}$ across (Fig. 2e). Based on the flaky morphology, the strong iron peak, and the 
reddish color, we interpret these grains to be hematite. The hematite is not widespread and may reflect more recent weathering.

\subsection{Summary of magnetic mineralogy data}

Our work suggests that carbonate strata throughout the mid-continent region contain four morphological classes (spheroidal, framboidal, botryoidal and flaky) of iron-rich and sulfur-free minerals. We estimate that, in general, spheroidal and framboidal grains account for about $25 \mathrm{ppm}$ of the rock. In all cases, the grains or aggregates are very small $(<20 \mu \mathrm{m})$, yield a strong iron peak, no titanium peak, and no sulfur peak in EDX spectra. There is an apparent morphological gradation between the spheroidal grains and framboidal aggregates, the difference being the degree to which octahedral microcrysts are obscured by a silicate (probably clay) coating.

Based on the EDX spectra and the octahedral crystal morphology, we consider the spheroidal grains and framboidal aggregates to be magnetite, in agreement with previous authors [e.g., 3,18]. The botryoidal aggregates could be magnetite, hematite, or goethite, and the flaky-habit aggregates are probably hematite.
To confirm the identification of these candidate magnetic minerals, we examined extracts using a very sensitive Rigaku X-ray diffractometer. The XRD pattern for the concentrated magnetic extract from sample IN0703 (fine-grained limestone; Middle Mississippian; sampled at southern Indiana) shows pronounced peaks for magnetite (Fig. 3 ) and the pattern for the scum obtained from the reagent after dissolving sample IL0207 (coarsegrained limestone; Pennsylvanian; sampled at central Illinois) shows subtle but identifiable peaks for hematite and goethite (Fig. 4). IRM acquisition curves for our samples, described by Kent et al. (in prep.), also point to the occurrence of magnetite in most samples and the co-occurrence of hematite at about one-quarter of the sampling sites. Further confirmation of the identity of the crystals will require X-raying of individual grains, if they can be isolated.

In sum, it appears that magnetite is the dominant magnetic mineral in mid-continent carbonate strata, and that it occurs as spheroidal clusters of octahedral microcrysts which may or may not be coated by clay and may occur individually or in botryoidal aggregates. If the coating is absent, the grain appears as a framboid, whereas if the coat-

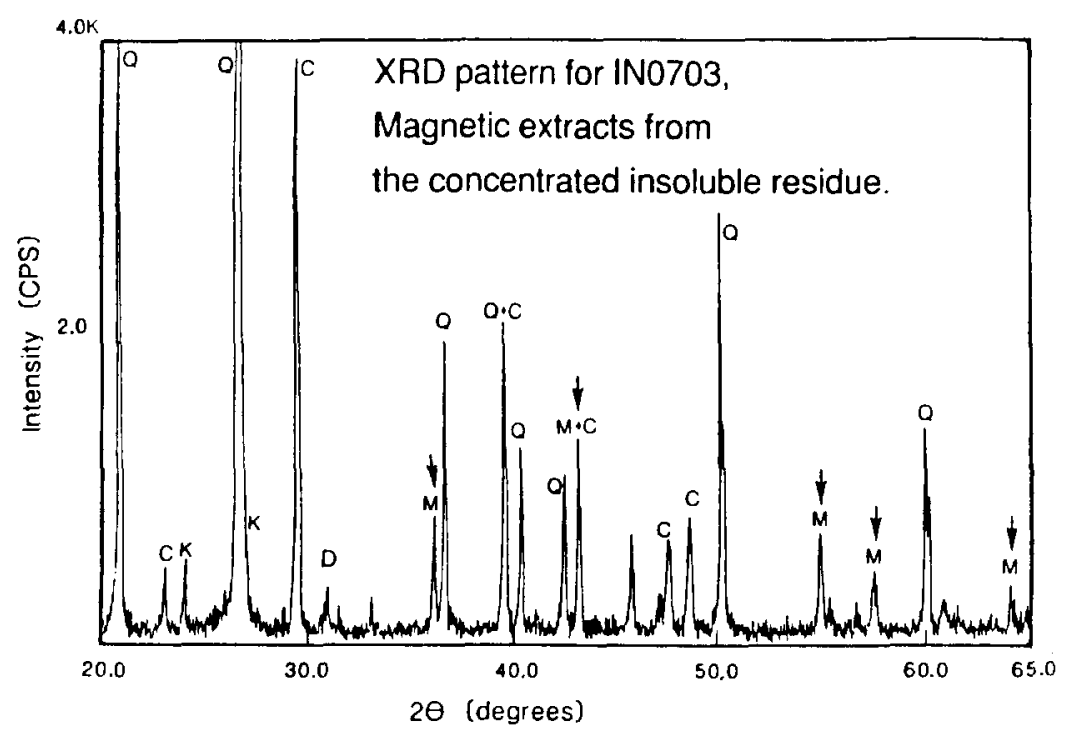

Fig. 3. XRD pattern obtained with Rigaku X-ray diffractometer for residue from sample IN0703. $Q=$ quartz; $C=$ calcite; $D=$ dolomite; $K=\mathrm{K}$-feldspar; $M=$ magnetite (indicated by arrows). Operation settings: voltage $=45 \mathrm{kV} ;$ current $=20 \mathrm{~mA} ; \mathrm{scan}$ speed $=12^{\circ} / \mathrm{min}$. 


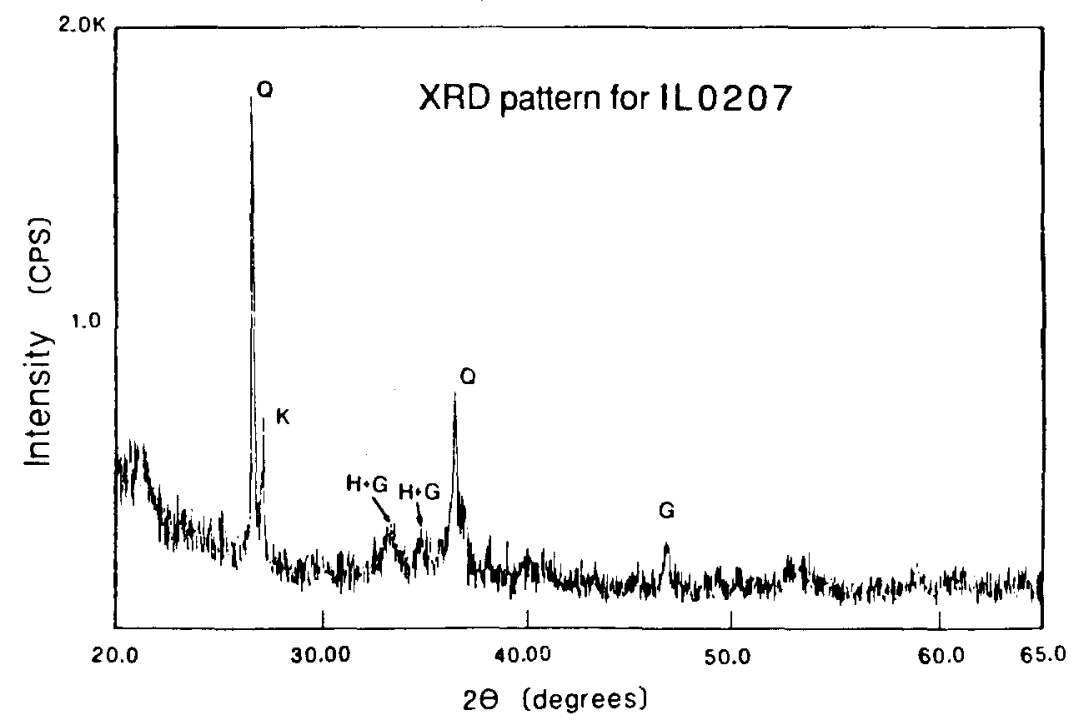

Fig. 4. XRD pattern obtained with Rigaku X-ray diffractometer for IL0207 (red scum taken from surface of reagent). $Q=$ quartz; $K=\mathrm{K}$-feldspar; $G=$ goethite; $H+G=$ hematite and goethite. Operation settings: voltage $=45 \mathrm{kV}$; current $=20 \mathrm{~mA}$; scan speed $=$ $6^{\circ} / \mathrm{min}$.

ing is present, the grain appears as a spheroid. Goethite sometimes occurs as a pseudomorphic replacement of pyrite and possibly as a surface coating on magnetite aggregates. Hematite also occurs in these strata, but of the ten samples that we analyzed, goethite and hematite were the common magnetic mineral only in one, suggesting that they may have formed only locally in response to near-surface weathering.

\section{Discussion}

\subsection{Origin of the magnetite}

The determination of whether the Kiaman remagnetization found in mid-continent rocks reflects chemical $[3,8]$ or thermoviscous [21] remanent magnetization requires knowledge both of the thermal history of the host rock and of the origin of the magnetite. Hypotheses concerning thermal histories of the carbonate strata in the mid-continent region favor the chemical remanent magnetization concept [22]. In this section we present observations concerning the origin of the magnetite that also favor the chemical remanent magnetization concept.

Whether the origin of the magnetite is authigenic (precipitated during diagenesis from a migrating brine or formed by oxidation of pre- cursor iron-bearing minerals like pyrite) or detrital (derived from terrestrial or cosmic sources and incorporated in the rock during primary sedimentation) is a subject for debate. If the magnetite is demonstrably authigenic, the remagnetization is more likely a chemical remanence. The magnetite spheroids and framboids that we observed in mid-continent carbonate strata are distinctly different from magnetite grains thought to be derived from a cosmic source. Cosmic grains typically have a smooth and shiny surface [23], reflecting the occurrence of a fused interlocking crystal mosaic [23,24]. They may also have dendritic structure [23], and radiating fibrous crystals [25]. None of these features were observed in the grains we examined. The euhedral octahedral crystal habit that we observed in the framboids of midcontinent rocks has not been observed in cosmic magnetite.

The composition of the magnetite in our samples is also indicative of an authigenic origin during diagenesis. Detrital magnetite grains derived from igneous sources would be expected to contain measurable amounts of titanium, which can diffuse into the magnetite lattice at igneous temperatures thereby forming a solid solution. Diagenetic magnetite, formed at relatively low temperatures $\left(<200^{\circ} \mathrm{C}\right)$ could not incorporate 
titanium.

The authigenic origin of the magnetite during diagenesis is circumstantially supported by the observation that the mid-continent strata contain abundant evidence of having been subjected to complex diagenesis related to flux of deep-basin brines through the rock [10]. Petrographic examination of the samples reveals features typical of diagenesis, such as neomorphism, silicification, and dolomitization. Dolomite rhombs show distinctive zoning, indicative of changing geochemical conditions during diagenesis. In many of the samples, we found authigenic K-feldspar, and in a few samples we found halite crystals. Authigenic pyrite is widespread in most samples, and occurs both in framboidal aggregates of octahedral microcrysts (Fig. 2f), as well as in larger cubic grains.

Finally, we note that the apparent structural control on the variation in magnetic intensity measured in our samples (our initial data indicates that stronger intensities were measured on the flanks of arches) also supports an authigenic origin. The flanks of arches are the sites of particularly strong diagenetic effects including deposition of ore deposits [10]. Thus, these sites would presumably be favorable locations for the reactions leading to authigenic magnetite formation. In contrast, there is no reason to expect a greater concentration of detrital magnetite at these locations, and it is not likely that these regions were buried particularly deeply to enhance thermal effects.

\subsection{Possible diagenetic history}

The evidence presented in this paper indicates that authigenic magnetite precipitated in mid-continent carbonate rocks across a broad region and that this magnetite is the carrier of the widespread Kiaman remagnetization that has been detected in these rocks. The association of dolomitization, smectite illitization, K-feldspar authigenesis [e.g. 26], and halite precipitation with remagnetization in mid-continent strata all favor the hypothesis that the remagnetization is a manifestation of regional diagenesis that occurred in response to the migration of brines through the strata, and that the remagnetization is a chemical remanence. The widespread distribution of remagnetization that we observed in the mid-continent indicates that this brine migration occurred on a continentwide scale [17]. The age of the remagnetization supports the idea that the brine migration occurred in a pulse triggered by intraplate or continental-margin tectonism that was roughly coeval with the Alleghanian/Ouachita orogeny [10]. Not all of the brines necessarily came from the Alleghanian/Ouachita orogen itself; some may have come from intracratonic highs $[10,27]$.

The original source of the iron in the magnetite could be pre-existing pyrite, iron-rich clay (which released iron during K-feldspar authigenesis), or iron transported into the local environment by migrating brines. The magnetite could pseudomorphically replace pre-existing pyrite or could precipitate directly as new microcrysts which accumulated into framboids in response to mutual magnetic attraction [cf. 28]. Considering that it is more efficient (i.e. requires less brine) to create authigenic minerals by alteration of existing species than by introducing new species, it is more likely that the magnetite in the mid-continent strata formed by alteration of pyrite and clay already in the strata. Pseudomorphic replacement or pyrite is favored by the observation that pyrite microcrysts (and host framboids) in mid-continent carbonates are comparable in size and shape to magnetite microcrysts (and host framboids), and by the discovery that such replacement occurs in estuarine sediments [29]. But the replacement concept is not compelling because we did not observe pyrite grains that had been partially altered to magnetite, and thus it is likely that some of the observed magnetite precipitated de novo.

The geochemistry of formation of diagenetic magnetite in mid-continent carbonates is not clear, for the reaction paths defining the fate of iron during reaction of warm brine with limestone are not yet well defined. Work by Garrels and Christ [30] and Bethke (oral commun., 1989) on modeling the reactions that occur when brines migrate through rock emphasize that the stability fields of magnetite, pyrite, and hematite depend on several variables including activity of oxygen, activity of sulfur, Eh, pH, salinity, and temperature. These variables were all changed regionally as warm brines passed through the mid-continent strata [e.g., 12,15,31]; alkalinity, salinity, and temperature increased. In the new environment, iron brought in with the brines may have precipitated as magnetite, but probably more importantly, local pyrite and clay reacted with the brine to yield 
ferric and ferrous iron. This iron precipitated as magnetite which pseudomorphically replaced preexisting pyrite grains or formed new microcrysts which then accumulated into framboids.

\section{Acknowledgments}

This work was supported by the Petroleum Research Fund of the American Chemical Society (grant $18680 \mathrm{G} 2$ to $\mathrm{S}$. Marshak) and by the National Science Foundation (grant EAR-88-03814 to D.V. Kent). We appreciate the assistance of R. Caldwell, W. Guo, and X. Gao in collecting the samples. We are also very grateful to S. Altaner, D. Henderson, C. McCabe, C. Chou, E. Daniels, M. Duffin, and many others, for their comments and discussions. The three anonymous reviewers were very helpful. Lamont-Doherty Geological Observatory contribution 4592.

\section{References}

1 R. Van der Voo, Age of the Alleghanian folding in the central Appalachians, Geology 7, 297-298, 1979.

2 C.R. Scotese, R. Van der Voo and C. McCabe, Paleomagnetism of the Upper Silurian and Lower Devonian carbonates of New York State: evidence for secondary magnetizations residing in magnetite, Phys. Earth Planet. Inter. 30, 385-395, 1982.

3 C. McCabe, R. Van der Voo, D.R. Peacor, C.R. Scotese and R. Freeman, Diagenetic magnetite carries ancient yet secondary remanence in some Paleozoic sedimentary carbonates, Geology 11, 221-223, 1983.

4 D.V. Kent and N.D. Opdyke, Multicomponent magnetizations from the Mississippian Mauch Chunk Formation of the Central Appalachians and their tectonic implications, J. Geophys. Res. 90, 5371-5383, 1985.

5 R.D. Elmore, W. Dunn and C. Peck, Absolute dating of dedolomitization by means of paleomagnetic techniques, Geology 13, 558-561, 1985.

6 C. Stearns and R. Van der Voo, A paleomagnetic reinvestigation of the Upper Devonian Perry Formation: evidence for Late Paleozoic remagnetization, Earth Planet. Sci. Lett. 86, 27-38, 1987.

7 J.D. Miller and D.V. Kent, Regional trends in the timing of Alleghanian remagnetization in the Appalachians, Geology 16, 588-591, 1988.

8 M. Jackson, C. McCabe, M.M. Ballard and R. Van der Voo, Magnetite authigenesis and diagenetic paleotemperatures across the northern Appalachian Basin, Geology 16, $592-595,1988$.

$9 \mathrm{~J}$. Oliver, Fluids expelled tectonically from orogenic belts: their role in hydrocarbon migration and other geologic phenomena, Geology 14, 99-102, 1986.

10 C.M. Bethke and S. Marshak, Brine migrations across
North America-The plate tectonics of groundwater, Annu. Rev. Earth Planet. Sci., in press, 1989.

11 C. McCabe, R. Van der Voo and M.M. Ballard, Late Paleozoic remagnetization of the Trenton Limestone, Geophys. Res. Lett. 11, 979-982, 1984.

12 D.L. Leach and E.L. Rowan, Genetic link between Ouachita foldbelt tectonism and the Mississippi Valley-type lead-zinc deposits of the Ozarks, Geology 14, 931-935, 1986.

13 C.M. Bethke, Hydrologic constraints on the genesis of the Upper Mississippi Valley mineral district from Illinois basin brines, Econ. Geol. 81, 233-249, 1986.

14 C.M. Bethke, W.J. Harrison, C. Upson and S.P. Altaner, Supercomputer analysis of sedimentary basins, Science 239, 261-267, 1988.

15 J.M. Gregg, Regional epigenetic dolomitization in the Bonneterre Dolomite (Cambrian), southeastern Missouri, Geology $13,503-506,1985$.

16 W.C. Elliott and J.L. Aronson, Alleghanian episode of K-bentonite illitization in the southern Appalachian Basin, Geology 15, 735-739, 1987.

17 S. Marshak, G. Lu and D.V. Kent, Reconnaissance investigation of remagnetizations in Paleozoic limestones from the mid-continent of North America, Trans. Am. Geophys. Union 70, 310, 1989

18 C. McCabe, R. Sassen and B. Saffer, Occurrence of secondary magnetite within biodegraded oil, Geology 15, 7-10, 1987.

19 R.D. Elmore, M.H. Engel, L. Crawford, K. Nick, S. Imbus and Z. Sofer, Evidence for a relationship between hydrocarbons and authigenic magnetite, Nature 325, 428-430, 1987.

20 M.J. Wisniowiecki, R. Van der Voo, C. McCabe and W.C. Kelly, A Pennsylvanian paleomagnetic pole from the mineralized Late Cambrian Bonneterre Formation, southeast Missouri, J. Geophys. Res. 88, No. B8, 6540-6548, 1983.

21 D.V. Kent, Thermoviscous remagnetization in some Appalachian limestones, Geophys. Res. Lett. 12, 805-808, 1985.

22 C. McCabe and R.D. Elmore, The occurrence and origin of late Paleozoic remagnetization in the sedimentary rocks of North America, Rev. Geophys. 27, 471-494, 1989.

$23 \mathrm{M}$. Zbik, Morphology of the outermost shells of the Tunguska black magnetic spherules: Proceedings of the Fourteenth Lunar and Planetary Science Conference, Part 2, J. Geophys. Res. 89, Suppl., B605-B611, 1984.

24 R. Freeman, Magnetic mineralogy of pelagic limestones, Geophys. J.R. Astron. Soc. 85, 433-452, 1986.

25 M. Hyman, E.B. Ledger and M.W. Rowe, Magnetite morphologies in the Essebi and Haripura CM chondrites: Proceedings of the Fifteenth Lunar and Planetary Science Conference, Part 2, J. Geophys. Res, 90, Suppl., C710-C714, 1985.

26 C. McCabe, M. Jackson and B. Saffer, Regional patterns of magnetite authigenesis in the Appalachian Basin: Implications for the mechanism of late Paleozoic remagnetization, J. Geophys. Res. 94, 10429-10443, 1989.

27 S. Marshak, D.V. Kent, and G. Lu, Tectonic reactivation in mid-continent North America: New insight from structural and paleomagnetic data, Geol. Soc. Am., Abstr. Programs 21, p. A81, 1989. 
28 G.R. Taylor, A mechanism for framboid formation as illustrated by a volcanic exhalative sediment, Miner. Deposita 17, 23-36, 1982.

29 G.W. Luther III, A. Giblin, R.W. Howarth and R.A. Ryans, Pyrite and oxidized iron mineral phases formed from pyrite oxidation in salt marsh and estuarine sediments, Geochim. Cosmochim. Acta 46, 2265-2669, 1982.
30 R.M. Garrels and C.L. Christ, Solutions, minerals and equilibria, 450 pp., Freeman, San Francisco, Calif., 1965.

31 P.P. Hearn Jr., J.F. Sutter and H.E. Belkin, Evidence for Late Paleozoic brine migration in Cambrian carbonate rocks of the central and southern Appalachians: Implications for Mississippi Valley-type sulfide mineralization, Geochim. Cosmochim. Acta 51, 1323-1334, 1987. 